\title{
Image of Excellence - Developing Wine Maps for Austria
}

\author{
Karel Kriz \\ University of Vienna, Department of Geography and Regional Research, Austria karel.kriz@univie.ac.at
}

Keywords: Thematic mapping, Cartographic Design, Geo-Communication

\begin{abstract}
:
The Austrian wine industry made the fundamental decision to intensify the marketing of Austrian wine via its origin. Therefore, the creation of protected wines of origin has once again become the focus of interest. Since the marketing of Austrian wine through vineyard designations is increasing every year, it is necessary to present Austria's vineyards in an informative way in order to bring the special features of the protected geographical origin of Austrian quality wines closer to the consumer. The comprehensive, precise and professional acquisition as well as appealing geographic map design of vineyards for different demands, tasks and presentations is widely seen as a conceptual framework for the dissemination of wine relevant issues.
\end{abstract}

Under this assumption, a collaboration project between representatives of the wine industry and academia came into being. Developing Wine Maps for Austria is an embedded research and development project with the aim of conceiving a functional as well as user-centered geographic communication portal of all Austrian vineyards to record, represent and communicate relevant factors dealing with wine and their spatial-temporal characteristics. The Austrian Wine Marketing Company (ÖWM Österreich Wein Marketing $\mathrm{GmbH}$ ) commissioned the project in cooperation with the University of Vienna, Department of Geography and Regional Research and the Technical Office for Landscape Planning plan+land, Artner \& Tomasits OG in order to promote the creation of protected wines of origin as well as to explore new horizons of geocommunication.

The project aims to establish a web portal that visualizes and disseminates information on Austrian vineyards in an effective and appealing way. Thus also communicating additional information to accentuate on wine specific features within a defined geographic entity. The goal is to play a pioneering role in the presentation of vineyards and associated products emphasizing in the objective of achieving (cartographic) image of excellence.

The presentation will discuss the general conceptual framework clarifying the communication structures and workflow within the system. Thereby explaining the methods and structures based on the defined system architecture. In this context the development and implementation of interfaces for the digital storage and manipulation of all decreed vineyards in Austria will be introduced. These are embedded in a geographical and political hierarchy. This paper will also focus on the prerequisites of wine maps as well as their digital representation with special emphasis on quality assessment and map design. It will compare and discuss currently accessible geo-data sources as well as online applications and finally present an approach to accommodate the described difficulties to facilitate sustainable data caption, creation and design for wine maps that must fulfill the conceptual framework. 